\section{RECEPCIONES DE LA OBRA DEL INCA GARCILASO EN EL SIGLO XVIII}

\author{
VIRGINIA GIL AMATE \\ Universidad de Oviedo
}

De sobra es conocida la fama del Inca Garcilaso y la vigencia de su obra en el siglo XVIII ${ }^{1}$. Menos evidente resulta, en cambio, considerar la diferente valoración que los autores dieciochescos le dieron, porque o bien funciona el tópico de que fue visto con general simpatía apenas contradicha por las diatribas de Cornelius de Pauw y algún otro detractor de lo americano, o bien se considera que su obra fue tan celebrada como utilizada de forma homogénea por parte de los criollos, o que suscitó desconfianzas desde España. Y esto no es exactamente así, porque la figura del Inca y el crédito que merecía su producción historiográfica estuvo sometido a variaciones que difícilmente se ajustan a parámetros sociológicos.

El primer cuarto del siglo ilustrado se inaugura, en lo que respecta al Inca Garcilaso, con la reedición de La Florida y los Comentarios reales en 1722-17232 auspiciada por Andrés González de Barcia. El hecho de que el editor y prologuista, bajo el pseudónimo de Gabriel Daza de Cárdenas, fuera una figura prominente del panorama cultural y político del momento, tanto en su labor de bibliófilo, compilador y editor de crónicas de la conquista y colonización de América, como en su calidad de miembro del Consejo de Castilla y fundador de la Real Academia Española ${ }^{3}$, habla, indirectamente, de la estima que la historiografía del Inca despertaba en las altas instancias culturales de la península. Es interesante el comentario de González de Barcia en el proemio a La Florida advirtiendo que el libro ha sido «mas deseado que conocido» ${ }^{4}$, debido a las dificultades de encontrar, adquirir y leer un ejemplar de la primera edi-

ción, por lo que la autoridad que se atribuía a la obra del Inca radicaba más en el autor que en el texto:

La verdadera sinceridad de esta Historia, hiço tan exquisito su Volumen, como elevado su precio. Aun adquirirle, para copiarle, era dificil. Muchos Aficionados, se contentavan, con la noticia, de averle escrito el Inca, fatigandose presto, en solicitarle; escasez, originada de aver debido, su primera Luz, à los ultimos fines de España, donde esparcidos pocos Egemplares, permanecieron menos, llevandoselos, ansiosos de saber nuestras Conquistas, los Estrangeros; hasta que siendo igual la falta, en todas partes, resumieron en varios Lenguages su contexto; manteniendose en todos siempre, con la estimacion, que mereció á los mas versados, en la Historia de las Indias Occidentales... ${ }^{5}$

Queda entonces el cronista al margen de cualquier duda sobre la fiabilidad de sus noticias, lo cual no deja de ser irónico en función de los reiterados temores de Garcilaso sobre la merma que su condición humana acarrearía a su obra. Al contrario, Barcia no duda en convertirse en portavoz de la noble fama que acompaña al autor:

Solo diré, que si antes de publicar esta Historia, todos miravan á su Autor, como Hombre Insigne, por su Religion, Nobleça, Virtud, Modestia, y Aplicacion á las Letras; despues le veneraron, hasta los Reies, como unico Historiador ${ }^{6}$.
Véase Edgar Montiel, «El Inca Garcilaso en el Siglo de las Luces», en I Encuentro
Internacional de Peruanistas: Estado de los estudios histórico-sociales sobre el Perú a finales del siglo XX, Lima,
Virginia Gil Amate:

Profesora Titular de Literatura Hispanoamericana de la Universidad de Oviedo. Es autora de la monografía Daniel Moyano. La búsqueda de una explicación (1993) y editora de los volúmenes Teatro de la emigración asturiana en Cuba (1997) y Escritores sin patria. La narrativa argentina de la segunda mitad del siglo $X X$ (2006). Ha publicado diversos artículos sobre narrativa hispanoamericana contemporánea, sobre el pensamiento político de la independencia hispanoamericana y sobre cronistas de Indias, entre ellos el Inca Garcilaso de la Vega y Juan Suárez de Peralta.

FCE, 1998, pp. 423-431; y «La influencia en el pensamiento de la ilustración. La genealogía del Inca Garcilaso», Identidades, 94 (2005), pp. 10-11. Puede consultarse igualmente el apartado que Belén Castro Morales dedica a los lectores dieciochescos del Inca Garcilaso en su excelente estudio «El Inca Garcilaso en los diarios de viaje de Alexander von Humboldt por el Tawantinsuyu», en Carmen de Mora y Antonio Garrido Aranda (eds.), Nuevas lecturas de "La Florida del Inca", Madrid/Frankfurt, Iberoamericana/Vervuert, 2008, pp. 223-270.

2

Véase Carmen de Mora, «En torno a las ediciones de La Florida del Inca», en Raquel Chang-Rodríguez (ed.), Franqueando fronteras, Lima, Pontificia Universidad Católica del Perú, 2006, pp. 213-233

3

Benito Sánchez Alonso, Historia de la historiografía española, vol. III, Madrid, Publicaciones de la Revista de Filología Española 1959 , p. 55-57.

4

«Proemio a esta segunda impresión, de Don Gabriel Daza de Cárdenas», en La Florida del Inca, Madrid, Nicolás Rodríguez Franco, 1723, p. 5 [b]. En el proemio, en la aprobación y en la censura de esta edición sólo aparecen numeradas las primeras páginas de cada cuaderno por lo que asignaré una letra a las cuatro páginas sucesivas indicándola entre corchetes. Ibid., p. 5 [a]. Ibid., p. 5 [b].

Recepciones de la obra del Inca Garcilaso en el siglo XVIII VIRGINIA GIL AMATE 


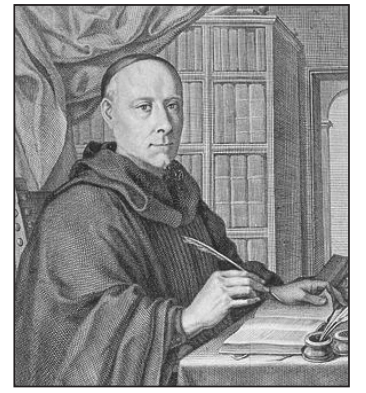

Benito Jerónimo Feijoo.

7

Ibid., p. 8.

8

Ibid., p. 8 [a].

9

Ibid., p. 8 [d].

10

Id.

11

Benito Jerónimo Feijoo, Carta XXX «Satisface el autor a una supuesta confusión sobre los sacrificios, que hacían los vasallos de los Incas del Perú, ofreciendo al Sol víctimas humanas» (1751), Cartas eruditas y curiosas, t. V. Madrid, Blas Román, 1781, pp. 514-515.

12

Gaspar Melchor de Jovellanos, Diario, 2으, en Obras Com pletas, tomo VII, María Teresa Caso y Javier González Santos (eds.), Oviedo, Instituto Feijoo de Estudios del Siglo XVIII, 1999, p. 76.

13

Ibid., p. 77.

Recepciones de la obra del Inca Garcilaso en el siglo XVIII VIRGINIA GIL AMATE
Postura corroborada por los redactores de las censuras y aprobaciones que, en este caso, abarcan La Florida y las dos partes de los Comentarios Reales de los Incas. Ni las fuentes indígenas, ni la transmisión oral de las noticias, ni la consaguinidad del Inca, fueron consideradas «heterodoxas», ni preocupante el sentido que Garcilaso daba a la historia del Perú o a la conquista de la Florida, según juicio de Fr. Francisco Montiel de Fuentenovilla, calificador de la Inquisición y firmante de la aprobación, de 30 de octubre de 1720, necesaria para la reedición de la obra historiográfica del Inca:

...hallo en todas estas Historias mucho, que admirar, sin cosa alguna que corregir: pues el Autor cumplió cabalmente con las Criticas Leies de la Historia, que son Verdad fundada en Fieles Testimonios, y Testigos Fidedignos, propiedad en las Voces, y energía en las Clausulas?.

Por su parte, el Cronista General de Indias, fray Pablo Yáñez de Avilés, aprovecha la censura fechada el 26 de mayo de 1722, para trazar una apología de España y contestar, esgrimiendo la obra del Inca, a las invectivas antiespañolas y a las disputas territoriales que ya arreciaban e irían aumentando según avanzara el siglo. Yáñez de Avilés, dado a la hipérbole, considerará a Garcilaso «el Historiador más Auténtico» y soportará con molesta desazón «quantas Sátiras, quantas Fabúlas, y quantas falsas Criminaciones» salen de las plumas de los «Hidropicos de nuestras Indias» ${ }^{8}$, salvo aquella que coloca como motor de la conquista la codicia española. Este extremo sí lo combatirá componiendo un largo fragmento sobre la riqueza natural de la Península Ibérica, cuyo colofón será, de nuevo, una alabanza personal del Inca por haber dotado de opulencia moral a la tierra donde yace y a la nación sobre la que escribe, ya que, para el fraile Bernardo no hay duda y así pasará con buena parte de los analistas penínsulares, las obras del Inca hablan de la historia gestada por los españoles:

Cordova es una de las Ciudades de Oro de nuestra España, y no es aora Ciudad de menos Oro, siendo Sepulcro del Gran Garcilaso de la Vega, Inca, Autentico Historiador, que en sus Escritos dejo el mejor Testimonio de los Españoles, hechos en los descubrimientos de las Indias?.
Antes de cerrar su censura, Yáñez de Avilés celebra que la reedición de La Florida y los Comentarios reales venga a salvar al Inca de «la avara prision de los Estantes de cara venta» ${ }^{10}$ pudiendo llegar a tantos lectores interesados. Testimonios de esta atracción hay a lo largo del siglo, pueden demostrarlo las palabras de Feijoo, que no ignoraba «el grande mérito del Inca Garcilaso, del qual leí una buena parte en mi juventud» ${ }^{11}$ o las de Jovellanos que, de forma tan sucinta como clara, muestra en su diario la favorable disposición de ánimo con la que comenzó, el 1 de febrero de 1795, la lectura del Inca («... al fin empezó Acebedo a leer la Historia del Inca Garcilaso...» ${ }^{12}$ ). Disposición anímica que parece mantener en días sucesivos:

Lunes, 2.- Viento largo y frío. Repaso de la Oración inaugural [del Real Instituto Asturiano], nuevo párrafo sobre la guerra. A misa. A visitar, de casa nueva, a Pepe María Rato y la Micaela Tineo. A casa. Viento recio y frío; más al vendaval. Intento de chimenea por la tarde, abandonado. Paseo en la playa; nueva tentativa; inútil. Gibbon; partida y al fin el Inca... ${ }^{13}$.

Si el interés de tan destacadas figuras de la Ilustración española parece ser semejante, no ocurre lo mismo con la valoración que les merecerá el historiador una vez conocida su obra. En el caso del Padre Maestro podemos contextualizar su juicio en los Comentarios reales $\mathrm{y}$, dentro de ellos, en los asuntos que atañen a los rituales cruentos, aunque no es tan importante el tópico tratado como el análisis sobre la naturaleza de la verdad histórica que transmite el Inca. A juicio de Feijoo entra dentro de la competencia del historiador seleccionar el contenido de su narración, por lo que no incidir en determinados temas no merma la veracidad del contenido. De este modo Feijoo comenzaba a construir uno de los pilares sobre los que se sostendría la defensa garcilasista desde José de la Riva Agüero:

Nada obsta contra esto la alegación, que V.S. hace de Autores, que dicen, que los sacrificios de los Peruanos eran frutos de la tierra, y de algunos animales. Tambien dicen esto los Autores, que he citado: el Padre Acosta en el lib. 5, cap. 18, y Herrera en el citado cap. 5 \$. I. Lo que se dexa entender del contexto de uno, y otro Autor, es, que los sacrificios de los brutos, y cosas inanimadas eran los cotidianos, y comunes; pero los de víctimas humanas sólo se practicaban en los casos extraordinarios, que ellos 
mismos señalaban y yo tambien señalé, siguiéndolos a ellos. Por tanto, si el Inca Garcilaso, ú otros Autores solo hablan de estos últimos sacrificios, es porque solo quisieron hablar de los de practica comun, y no de los extraordinarios. No ignoro el grande mérito del Inca Garcilaso, del qual leí una buena parte en mi juventud; hoy no le tengo, ni aquí hay quien le tenga. Pero en ninguna manera se opone á su veracidad, y buena fe el que omitiese la relacion de los sacrificios, que se hacian extraordinariamente, contentándose con dar noticia de los anuales, y diarios. No ignoro que los Incas reformaron infinito de la barbarie dominante en los Reynos que conquistaron, y que estos fueron por la mayor parte unos Príncipes muy magníficos, de insigne conducta, y acertado gobierno; pero adonde reyna la Idolatria, por mas que los Príncipes sean bien intencionados siempre queda un resto de barbarie ${ }^{14}$.

Por su parte, Jovellanos no hace constar en el Diario el volumen que lee, aunque no sería desatinado, en función de las alusiones a la «tradición» que sigue el Inca, pensar que se refiere a los Comentarios reales. De todas formas no es tan necesario ajustar el contexto porque el juicio de Jovellanos es lapidario y general hacia el historiador:

Acebedo leyó en el Inca ¡Valiente patrañero me parece! Creo que siguió el fama sequere pero no el sibi convenientia finge de Horacio ${ }^{15}$.

Sería difícil achacar tan encontradas opiniones a un cambio de percepción histórica según avanzaba el siglo XVIII, porque de ambas tendencias encontraremos señeros representantes en el último cuarto de la centuria.

Buen ejemplo de una atenta lectura del Inca es la impresión mantenida por José Cadalso diferenciando, desde su punto de vista de militar ilustrado, a través del diálogo entre Nuño y Gazel en las Cartas marruecas (1775), la heroica conquista de México frente al barullo sanguinario ocasionado en Perú. No alude en la Carta IX, la referida a los juicios que la conquista genera a esas alturas del siglo XVIII, al Inca, pero esta era la única fuente medianamente directa publicada en la época en lo que respecta a la conquista del Tahuantinsuyo y, efectivamente, el curso narrativo de los Comentarios reales no invita, a pesar de razonamientos curiosos como el de Yáñez de Avilés, a exaltaciones patrióticas. Además, ya había dejado constancia de la alta estima que profesaba al cronista peruano en Los eruditos a la violeta (1772), ese curso burlón dedicado a aquella especie común en la centuria de los que pretendían «saber mucho, estudiando poco»16. En la «Séptima Lección», el maestro Joseph Vázquez recomienda, para alcanzar la palma de la pseudoerudición, no perder el tiempo con los que han enseñado el verdadero curso de la historia, sino dedicarse a la elucubración insensata sobre la validez y la consistencia de los hechos, prescindiendo de -y aquí va el catálogo de autores que le parecen valiosos en la materia- Plutarco, Tácito y Suetonio, para la historia antigua; y Mariana, Herrera, Bernal Díaz del Castillo, Antonio de Solís y el Inca Garcilaso, para la historia de «las Españas» ${ }^{17}$.

También Juan Andrés destacará en su monumental Origen, progreso y estado actual de toda la literatura (1782-1799) la elocuencia del Inca Garcilaso:

El descubrimiento de América presentó anchuroso campo à los historiadores españoles para explayar su eloqüencia; y dexando a parte à Diaz del Castillo, à Gómara y à otros infinitos, muchos de los quales pueden verse en el Catálogo de los libros de manuscritos españoles examinados por Robertson, que va junto con su historia ¿̇no bastan Herrera y Garcilaso de la Vega para hacer inmortal el nombre español en la historia de América?18.

No merma el elogio a Garcilaso comprobar que no calaron en el padre Andrés las noticias del incario contenidas en los Comentarios reales, puesto que no tendrá en cuenta a los pueblos prehispánicos de América en el recuento de las naciones que han dejado alguna huella cultural en el decurso del tiempo. Bien es cierto que el concepto de literatura que maneja ${ }^{19}$ se ciñe a las «Buenas letras» y a las «Letras humanas», es decir a lo escrito, y eso le impide la referencia a las manifestaciones vernáculas del continente. Pero igualmente es evidente que la admiración por el Inca no despertó su curiosidad hacia lo americano, prueba de ellos es la omisión, en el apartado dedicado a la historia anticuaria, en el capítulo destinado a los gramáticos, y en el de los estudiosos de la cronología, de los autores que transmitieron noticias sobre las antigüedades de Indias.

La fascinación provocada por Garcilaso se ve atenuada cuando el que escribe no se detiene en el arte verbal y pretender refrendar datos concretos. Eso ocurre en El lazarillo
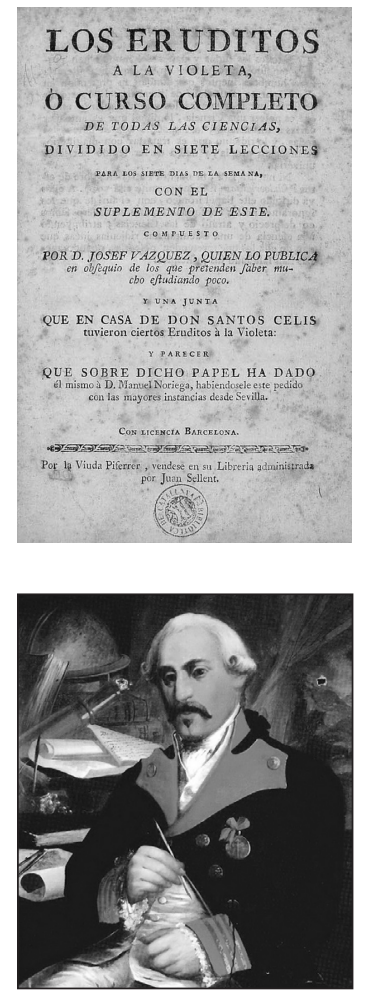

José Cadalso.

14 Benito Jerónimo Feijoo, op. cit., pp. 514-515.

15

Gaspar Melchor de Jovellanos, op. cit., p. 78.

16

José Cadalso, Los eruditos a la violeta, Nigel Glendinning (ed.), Madrid, Anaya, 1967, p. 43.

17 Ibid., p. 118.

18

Juan Andrés, Origen, progreso y estado actual de toda la literatura, t. VI, Madrid, Imprenta de Sancha, 1793, p. 148.

19

Véase Inmaculada Urzaínqui, «El Parnaso español en la his toria literaria del siglo XVIII», Bulletin Hispanique, t. 109, 2 (diciembre 2007), pp. 643-684.

Recepciones de la obra del Inca Garcilaso en el siglo XVIII VIRGINIA GIL AMATE 


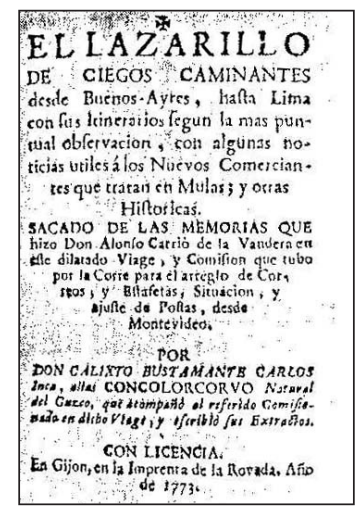

20

Alonso Carrió de la Vandera, El lazarillo de ciegos caminantes, Antonio Lorente Medina (intro, crono. y biblio), Caracas, $\mathrm{Bi}$ blioteca Ayacucho, 114 (1985), p. 134.

21

Véase John H. Rowe, «El movimiento nacional inca del siglo XVIII», Revista Universitaria (Universidad Nacional de Cuzco), 107 (1954), pp. 17-47.

22

Alonso Carrió de la Vandera, op. cit., p. 256.

23

lbid., p. 257.

24

lbid., p. 256

25

lbid., p. 257.

Recepciones de la obra del Inca Garcilaso en el siglo XVIII

VIRGINIA GIL AMATE de ciegos caminantes (1773), donde Alonso Carrió de la Vandera refutará en parte las noticias del Inca sobre el sistema de comunicaciones del Tahuantinsuyo:

La segunda posta está situada en un corto pueblo nombrado Tiay-Huanaco, que significa «siéntate guanaco", que es un animal que corre tanto como un venado. Este nombre quedó de uno de los Incas, que hallándose en aquel sitio recibió un correo con tanta velocidad como si le hubiera conducido un guanaco. Esto mismo prueba que no siempre los correos estaban a cortas distancias, como dice el Inca Garcilaso, por que los indios apostados no entendían los quipus ni se detenían a formar partes, porque en ese caso no serían tan veloces las carreras. Éste, desde luego, sería algún extraordinario muy diligente ${ }^{20}$.

Claro que ajustar la información no es denigrar al cronista. Al contrario, Carrió de la Vandera demuestra ser un interesante lector del Inca al actualizar una lectura política de lo que la figura del Inca Garcilaso podía representar en un Perú convulsionado por las insurrecciones indígenas ${ }^{21}$. Contrariamente a la acción gubernamental, manifestada en la cédula real de 1782, instando a los virreyes a recoger con discreción los Comentarios reales para alejar a los naturales de semejante foco de noticias, permutando la otrora valoración institucional que encontraba en la obra del Inca un glorioso testimonio histórico de la acción colonizadora para pasar a considerarla un documento de cariz indigenista, Carrió sigue pensando en su Plan de gobierno del Perú (1782), que la obra del Inca puede mantener su sentido integrador original siempre y cuando se rompan de una vez en América las barreras, jurídicas y mentales, que encapsulan en entidades poblacionales diferentes a los españoles y a los mestizos. Al calor de la insurrección de Tupac Amaru II, en la que se concentra un largo siglo de sublevaciones contra el orden hispánico, se apoya en Garcilaso para destacar que no es ningún demérito ser mestizo - «Garcilaso no desdeñó, en su Historia del Perú, llamarse mestizo y hacer un apóstrofe a sus paisanos mestizos» ${ }^{22}$ - No desconoce, sin embargo, que en el setecientos los avances sociales no habían conseguido mermar la impronta del criterio de «calidad» aplicado a los individuos en función de su nacimiento y condición racial, y más en los estamentales virreinatos americanos. Carrió convive con esa realidad sin compartir sus presupuestos - «desengañémonos y confesemos que no hay mestizos, que es lo más cierto, o que todos lo somos» ${ }^{23}-$, abogando, en términos políticos, por la incorporación plena de los mestizos al estamento de los españoles - «Ya llevo dicho que los mestizos deben reputarse como españoles y hacer con ellos un solo cuerpo, y gozar de los mismos privilegios» ${ }^{24}-$. Presupuesto que hace visible dos aspectos, al menos, de la mentalidad del autor: uno que rompe con los prejuicios de limpieza de sangre, tantas veces manifestado en las gruesas bromas sobre el origen lanzadas por Concolorcorvo y por el visitador D. Alonso en El lazarillo de ciegos caminantes; otro, proyectado sobre la realidad coetánea, en la que su propuesta política pasa por la solidaridad de todos los que pueden defender el orden hispánico, es decir, el presente histórico emanado de la conquista, frente a las pretensiones de vuelta al incario:

Todas estas razones, y otras que omito, me obligan a persuadir a los que trataban antes de mestizos por vituperio, desde hoy los admitan los españoles como iguales y que alternen con ellos sin fastidio, para que así, unidos y en buena armonía, podamos rechazar $\mathrm{y}$ aun subordinar al numeroso populacho de que estamos por necesidad rodeados ${ }^{25}$.

En este aspecto es interesante detenerse en el párrafo que dedica, dentro del Plan de gobierno del Perú, a la diferencia en la actitud con la que se aborda el origen desarrollada en México y en Perú, contraponiendo el orgullo de Garcilaso por sus ancestros españoles e indios -similar a la práctica de muchos mexicanos a través de los siglos virreinales-, con la negación u ocultación de ese mestizaje por parte de los peruanos. El párrafo, un tanto farragoso, camufla la realidad ya que el funcionario no podía desconocer que las reclamaciones de los caciques indígenas, desde la rebelión de Juan Santos en 1742 hasta la definitiva de José Gabriel Codorcanqui de 1780 , pasaba por la reivindicación de una continuidad incásica paralela al desarrollo del Perú. En la flagrante adulteración reside la idea de Carrió de la Vandera, cuya fuerza estaría en fidelizar al orden vigente a un amplio segmento de la población virreinal, pero para trocar la pulsión indigenista en vertebración hispánica se impone la necesidad de integrar, aceptar, e incluso enorgullecerse, del ancestro indígena: 
Los conquistadores ya sé que ni todos fueron Garcilasos ni lograron casarse con princesas, pero es natural que eligiesen para esposas las más principales del reino. Los mejicanos han sido más curiosos que los peruleros en conservar su genealogía desde la conquista, y no se desdeñan de toparse con una india noble o con un indio principal que logró casar con una española, y con esto prueban una nobleza de 300 años sin salir de su tierra; y finalmente, desengañémonos y confesemos que no hay mestizos, que es lo más cierto, o que todos lo somos ${ }^{26}$.

Con mayor radicalidad evidenció una idéntica mentalidad defensiva frente a los indios José Eusebio del Llano Zapata - «Nos han costado mucho los Indios, y nos costarán algo más, mientras no rayasse la lúz en el numeroso gentilismo, que nos cerca» ${ }^{27}-\mathrm{y}$ eso que cuando expresa sus consideraciones sobre la agresividad indígena contra el orden hispánico en el Perú todavía no se había producido la insurrección de Condorcanqui. Las apreciaciones de Llano Zapata se encuentran expuestas en las cartas que cruzó con Gregorio Mayans durante su estancia en España a mediados de siglo ${ }^{28}$. El erudito valenciano había respondido, el 27 de noviembre de 1757, a la misiva enviada por el criollo comunicándole sus proyectos. Mayans abogaba, en lo que respecta a la historiografía, por la veracidad de la información de Las Casas y especulaba con la necesidad, y extrema dificultad, de acometer una obra sobre la colonización de América «en la que no aparezca abominable la ruina que causaron en el Nuevo Mundo los conquistadores españoles» ${ }^{29}$. El ilustre criollo respondió en carta fechada en Cádiz el 21 de mayo de 1758 con una ardorosa defensa de la conquista que albergaba un furibundo ataque al dominico - «os Authores, que, como el Ilustrissimo Casas, escriben con sangre, dexan a la posteridad más bien libelos que historias. Los Escritos de este Prelado donde quiera que tocan, queman...»30- y, en clara referencia a la actualidad del Perú, contra argumentaba haciendo que la generalización utilizada por Las Casas no respondiera sino a casos concretos y aludiendo, como hecho cierto - «vivimos todos los que las hemos oído, y visto» ${ }^{31}-$, a la peligrosidad indígena -«Quantas atrocidades (imponderablemente mayores) han hecho, y hacen hasta hoy los Indios con los Españoles. Muy buen testigo soy yo, y lo son todos los que hoy viven en el Perú, Chile y Buenos Ayres» ${ }^{32}-$, dando en prueba las continuas incursiones de los indios Pampas, la sublevación de «el antiguo Trahidor, y Apostata Juan Santos Atahuallpa» ${ }^{33}$ y la insurrección de 1750 comandada por Francisco Inca en Huarochiri, por todo ello sobran motivos para escribir una

Destruccion de los españoles por los Indios. Entonces vería el Mundo, quienes hán derramado mas sangre, si los Nuestros, ó los Indios. Facil es de decidirlo. Estos hasta hoy la derraman. Los Nuestros há casi 200 años, que envaynáron la espada, haciendole solo las Conquistas con el Estandarte de la Cruz. Y si alguna véz ponen en arma contra estas gentes, es solo, para defender la Religion, el Rey y la Patria ${ }^{34}$.

Por supuesto, el antilascasismo de Llano Zapata no lo aleja del Inca Garcilaso. Tampoco su negativa visión de los indígenas opuestos al orden hispánico nos permitiría presuponer una postura diferente de la mantenida por Carrió de la Vandera en lo que atañe a los mestizos, no en vano ambos viven bajo las mismas circunstancias, las de la población española del Perú. Además, documentos hay que prueban las defensas explícitas que sostuvo de los méritos de indios y mestizos integrados en la sociedad virreinal y sus peticiones para que les fueran reconocidos, por eso mismo, el derecho a las mismas prerrogativas de las que gozaba el colectivo de españoles ${ }^{35}$. Sin embargo, Llano Zapata tiene una valoración negativa del cronista $^{36}$ que atañe a la veracidad de su obra y eso sí lo separa de Carrió. Veamos, Mayans había autorizado en el Inca Garcilaso, en Fernando Pizarro y Orellana y en Francisco Caro de Torres sus noticias sobre las guerras civiles del Perú y la consideración judicial e histórica que estas depararon a los Pizarro. En su respuesta el criollo sólo comentará lo dicho por los dos últimos, mientras las referencias a los Comentarios reales no pasarán de una cita con la que deslegitimar la obra y la persona de Las Casas, junto con un ajuste de la información que el cronista mestizo da sobre el dominico. El Inca no estará en la nómina de autores que le parecen fiables para acceder a la historia de la América meridional:

Quando yo por incidencia vierto en mis notas algunos passages históricos, soy imparcial en la relación de ellos. Bien veo, que para esto tenèmos pocos authores, y de estos pocos, algunos que rebaxar. Son los mejores entre los Antiguos Zarate, el Señor
26

Ibid., pp. 256-257.

27

José Eusebio del Llano Zapata, Preliminar y cartas que preceden al Tomo I de las Memorias Historico-physicas, critico-apologeticas de la América Meridional, Cádiz, Oficina de D. Pedro Gómez de Requena, 1758, p. 57.

28

Para la relación epistolar entre Mayans y Llano Zapata véase Antonio Mestre, Apología y crítica de España en el siglo XVIII, Madrid, Marcial Pons Historia, 2003, pp. 29-32.

29 Ibid., p. 30.

30

José Eusebio del Llano Zapata, op. cit., p. 52.

31 lbid., p. 56.

32

ld.

33

Id.

34

lbid., p. 57.

35

Puede comprobarse en la defensa que Llano Zapata realizó de D. José Joaquín Ávalos y Chauca, véase Copia de la carta que con fecha de 29 de Abril de 1774, escribe al Illmo. Y Revmo. Señor D. Fr. Francisco de los Rios, Obispo de Panamá, D. Joseph Eusebio del Llano Zapata, sobre la adelantada Maduréz, y rapidos progresos Literarios de un insigne Theólogo, y Canonista de la Real Universidad de Lima (Universidad de Oviedo, Biblioteca Central).

36

Sin embargo, José Antonio Mazzotti considera que hay un "consenso criollo sobre los Comentarios» en "Garcilaso y los orígenes del garcilasismo: el papel de los "Comentarios reales» en el desarrollo del imaginario nacional peruano», Fronteras. Revista del Instituto Colombiano de Cultura Hispánica, 3: 3 (1998), pp.13-35.

Recepciones de la obra del Inca Garcilaso en el siglo XVIII VIRGINIA GIL AMATE 


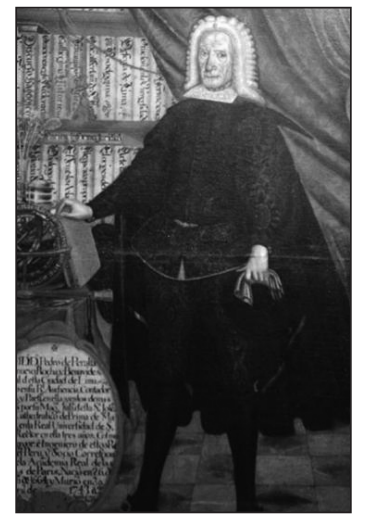

Pedro de Peralta y Barnuevo.

37

José Eusebio del Llano Zapata, op. cit., pp. 34-35.

38

Ibid., pp. 35-36.

39

Ibid., p. 79.

40

Pedro de Peralta Barnuevo, Lima fundada o conquista del Perú, Manuel de Odriozola, ed., Colección de documentos literarios del Perú, Lima, Establecimiento de tipografía y encuadernación de Aurelio Alfaro, 1863, p. 239.

\section{1}

José Antonio Mazzotti ha estudiado el peso del Inca Garcilaso en la Descripción de las Fiestas Reales o Júbilos de Lima de Peralta Barnuevo, véase «La invención nacional criolla a partir del Inca Garcilaso: las estrategias de Peralta Barnuevo», en Daniel Castillo Durante y Borka Sattler (eds.), Perú en su cultura, Otawa, Ediciones Legas, 2000, pp. 55-72.

42

Pedro de Peralta Barnuevo, op. cit., Canto II, nota 18, p. 40.
Recepciones de la obra del Inca Garcilaso en el siglo XVIII VIRGINIA GIL AMATE
Pinelo, y el M. Calancha. Entre los Modernos el P. Ovalle, D. Pedro Perálta, y D. Antonio de Ulloa. Registraron ellos los Archivos, y Memorias, que en Quito, Lima, Cuzco, Charcas, y Chile conserva la Antiguedad con instrumentos authenticos. No todos vieron todo. Pero juntos hacen un cuerpo de Historia mas segura, que las que otros hasta aquí han publicado ${ }^{37}$.

Ni siquiera cita al Inca Garcilaso cuando, a las autoridades hispánicas, añade la necesidad de tener en cuenta los soportes indígenas de la memoria histórica, obviando la pionera recuperación de dichas fuentes en los Comentarios reales:

...los Quipus, ó Amales, que aun a pesar del desprecio, y la ignorancia, hasta hoy se encuentran algunas reliquias de ellos en templos arruinados, palacios destruidos, y otros monumentos de la antiguedad. Los que verdaderamente si se huvieran tenido, como el más precioso thesoro de Nuestras Indias, servirían a la Historia de aquella lúz, que apenas hoy podemos encontrar en tan grande obscuridad, y confusión de noticias, si queremos averiguar los Orígenes de aquella Vasta Monarchia ${ }^{38}$.

$Y$ no es de extrañar, porque el descrédito en el que Llano Zapata tiene al Inca es absoluto, no le servirá para autorizar la verdad histórica, ni le reconocerá competencia ligüística alguna. De manifiesto queda en el apartado que dedica a contestar la apreciación de Mayans sobre la españolidad del término «canoa» basándose, como todos los que han sostenido tal hipótesis, en la errónea fecha de edición atribuida al Vocabulario españollatino de Antonio de Nebrija. Llano Zapata abunda en la cuestión, traza una etimología cuando menos dudosa para el término y despacha al Inca Garcilaso apoyándose en unos datos biográficos inexactos:

Este Sabio Cuerpo [la Real Academia Española], siguiendo al Inca Garcilaso, se engañó en su Diccionario [...]. El Inca dixo lo que quiso, é interpretó la voz a su arbitrio, y sin mas fundamento, que su antojo. Solo supo él muy poco de la Lengua Quechua, que era la general del Perú, donde nació. He dicho muy poco, porque vino a España niño, y apenas tuvo tiempo para instruirse en todas las voces, propiedades, elegancias, y phrasses de aquel Idioma. Assi su authoridad es de ningún peso, para establecer la legitimidad de la voz canoa, que en ningún tiempo ha sido americana ${ }^{39}$.
Claro que nada de ello marca una línea de interpretación criolla puesto que antes de que Llano Zapata desvirtuara los saberes de Garcilaso, Peralta Barnuevo había vindicado su figura en el recuento de autores ilustres del Canto Séptimo de Lima fundada o conquista del Perú, considerándolo el iniciador del parnaso peruano y el nombre más destacado del mismo:

\section{CLIV}

Los júbilos preven y los honores

Para el que del austral docto Parnaso

Primogénita es luz de sus ardores,

Todo lo es el famoso Garcilaso:

El que para llevar tus esplendores

A la inmortalidad, tan firme el paso

De su juicio dará, que tus doseles

Le deban la mitad de sus laureles ${ }^{40}$.

No se limitará Peralta a ponderar su magnífico estilo verbal, al contrario, Garcilaso será una de las autoridades recurrentes, junto a Gómara, Cieza y Zárate, para los asuntos de la conquista evocados en los versos y avalados como hechos históricos en las notas al pie. Pero no es una mera alabanza y un recuento de citas la medida del calado del Inca en Peralta ${ }^{41}$, esta se advierte al comprobar que el poema sigue, en aspectos fundamentales, el sentido que Garcilaso dio al curso de la historia. Considerará el poeta a los emperadores del Tahuantinsuyo, según se hace en los Comentarios reales, como los pretéritos civilizadores de la región, que en nobles conquistas destruían «la vaga adoración de ídolos torpes, como de canoas y peces y otros inmundos animales, los sacrificios de carne humana, el vicio nefando y otros en que incurrían los pueblos salvages» ${ }^{42}$. No faltarán las semblanzas laudatorias de los Incas, a las que dedica el Canto II y, al llegar a la desmembración del imperio en tiempos de Huayna Cápac, sigue al cronista en su afinidad a Huascar:

\section{XXV}

Este [Quito] á Atahualpa lo dejó, impelido

De un tierno amor que le cegó lo sabio:

A Huascar el del Cuzco desunido

Imperio dio con ominoso agravio:

Así dos enemigos ha instituido

Cláusula necia de prudente labio:

¡Oh cuanto yerra el que hace de sus estados

Por dejar un feliz, dos desgraciados! 


\section{XXV}

Así Atahualpa al infeliz hermano

Cauteloso formó súbita guerra,

En que cortó del tronco soberano

Las ramas dignas de imperar la tierra:

Al Huascar luego con rigor tirano

En dura cárcel prisionero encierra:

Y así, pues, es, quien contra si os alista,

El mismo se ha empezado la conquista ${ }^{43}$.

Tampoco en Peralta la hermosa vivificación del Incario mermará la talla de los conquistadores españoles, ni siquiera en los pasajes más controvertidos. Por ejemplo, en el Canto III, al recrear el parlamento entre Pizarro y Atahualpa en el que el monarca de Quito rechaza la fe y el vasallaje ofrecido por el padre Valverde, sigue a Garcilaso como autoridad más fiable al coincidir la narración que el cronista hizo de los hechos con las expectativas de verosimilitud dieciochescas, según explica en la nota 2 a la estrofa III:

Según parece de la oración de Fray Vicente de Valverde, que sacada del P. Blas Valera pone á la letra Garcilaso par. 2. 1. I. c. 21. fué mucha luz á un tiempo la que pretendió dar al Inca, con misterios que necesitaban de mas explicación. Y según otros autores, que cita en el cap. 23. fué muy seca y áspera, á que se añadió la mala interpretación del Faraute, el indio Felipe, que no entendía lo mismo que interpretaba; de suerte que, por decir Dios Trino y uno, dijo: Dios tres y uno son cuatro. Lo que dicen del enojo con que el Inca arrojó los Evangelios y de las voces con que Fray Vicente llamó al arma, es falso según Garcilaso par. 2 lib. I cap. 26. y se hace inverosímil en un Santo Religioso, siendo tan contrario á su carácter ${ }^{44}$.

Garcilaso seguirá figurando como sólida apoyatura en las apariciones milagrosas que acompañan a la conquista a lo largo del Canto IX, entre ellas la providencial del apóstol Santiago cuando los españoles se encontraban sitiados en Cuzco por Manco Inca (octava LXXVIII), o las reiteradas de la Virgen (octavas XCV y XCVI) en momentos claves de la campaña. Sin embargo, no estará Garcilaso citado en la nota adjunta a la octava CIX dentro de los historiadores de los que «no puede dudarse por su insigne autoridad y número» 45 que avalan el amparo del que gozaron los conquistadores. Ahí sí hay una sutil diferencia en la apreciación de los fenómenos sobrenaturales, porque Peralta los considerará «favores» que la providencia a «América destina» ${ }^{46}$, mientras el Inca dejó escapar su amarga ironía - «Y con esto bolveremos a nuestros españoles, que, con tales favores, ¡qué mucho que ganen cien mundos nuevos! ${ }^{47}$ - ante tal sectarismo divino en pro de los conquistadores.

Por su parte, José Martín Félix de Arrate y Juan Pablo Viscardo, unidos por su acendrado orgullo criollo y, obviamente, separados por el punto de vista político con el que contemplaban la incardinación de los territorios americanos a la Corona española, celebraban, sin fisuras, la veracidad historiográfica del Inca. El cubano, en Llave del Nuevo Mundo (1761) cita con profusión La Florida tanto para avalar sus noticias históricas como para probar los nobilísimos orígenes de los descendientes de los conquistadores y primeros pobladores de la isla. Por tanto, si las obras del Inca sirvieron, a lo largo del siglo XVIII, para acreditar el linaje incásico de los caciques indígenas, no menor servicio les prestaron a los españoles americanos. Arrate buscó en La Florida la calidad de Vasco Porcallo de Figueroa y sus descendientes ${ }^{48}$; y a los Comentarios reales remitirá, entre otros, Diego Joseph Carrillo de Abornoz, Regidor perpetuo de la ciudad de Lima, en la relación de méritos enviada al Consejo de Indias a mediados de siglo ${ }^{49}$.

Pero Arrate no utiliza al Inca como una mera cita, su autoridad pasa a ser central al encarar la desaparición de la población vernácula basando en La Florida el argumento del suicidio masivo:

No puedo negar que deshicieron las expuestas cualidades por pusilánimes, o demasiadamente inclinados al ocio y descanso, buscando por remedio contra la indispensable necesidad del trabajo la última desesperación de ahorcarse, pues afirma el Inca (Histor. de la Flor., c. 12) se hallaban diariamente las casas despobladas de vivientes y llenas de cadáveres, de que hasta ahora se conservan osarios en algunas espeluncas o cuevas del contorno, a donde debían también de retirarse a quitar por sus mismas manos las vidas ${ }^{50}$.

A abundar en la cuestión con notable ligereza dedicará el capitulo VI, destacando en todo momento la fiabilidad de Garcilaso para probar algo que el Inca no hizo, considerarla razón suficiente de la depresión demográfica y exonerar de culpa alguna a los conquistadores para que ninguna mancha de origen marcara a los criollos del setecientos, sus descendientes:

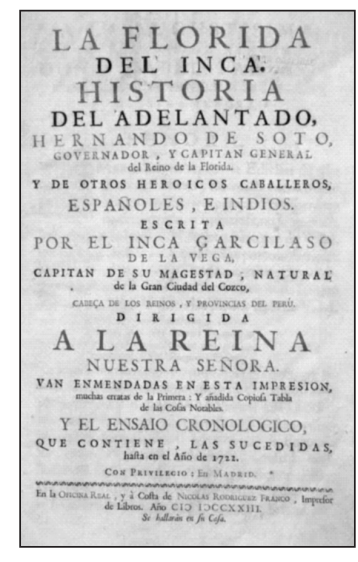

43

lbid., p. 38.

44

lbid., p. 52.

45

Ibid., p. 339

46

lbid., p. 341

47

Garcilaso de la Vega, Inca, Historia general del Perú. Segunda parte de los Comentarios Reales de los Incas, Ángel Rosenblat (ed.); José de la Riva Agüero (pról.), Buenos Aires, Emecé, 1944, Libro II, cp. XXV, p. 183.

48

José Martín Félix de Arrate, Llave del Nuevo Mundo, México, FCE, 1949, p. 97.

49

Relación de los méritos y servicios, executados desde la conquista de las Indias por diversos ascendientes de Don Diego Joseph Carrillo de Albornoz, conde de Montemar, Señor del Castillo de Miravel, Escribano Mayor del Mar del Sur, y Regidor perpetuo de la Ciudad de Lima, 12 de septiembre de 1755, Biblioteca Central de la Universidad de Oviedo, Librería del Conde de Toreno, Ms. H., pp. 149-155.

50

José Martín Félix de Arrate, op. cit., p. 19.

Recepciones de la obra del Inca Garcilaso en el siglo XVIII VIRGINIA GIL AMATE 
52

Véase Belén Castro Morales, op. cit.

53

Alexander Von Humboldt, Ensayo político sobre la isla de Cuba, París, Libreriade Lecointe, 1836, p. 129.

Recepciones de la obra del Inca Garcilaso en el siglo XVIII VIRGINIA GIL AMATE
Siempre será lamentable a los buenos patricios aquella fatal y lastimosa época en que, empezando a hacerse visible y casi inevitable la acelerada disminución de los naturales de la Isla, pronosticó como en las demás de barlovento el total exterminio del considerable número de indios que la habitaban al ingreso de Don Diego Velázquez en ella [...] parece que subsistió la Isla sin conocida decadencia poco espacio de tiempo, porque el año de 1523 ó 1524 ya muerto el Adelantado dio el Rey permiso para introducir en ella trescientos negros: providencia a que sin duda daría motivo la evidente disminución de los naturales, que aunque atribuida por unos a la epidemia de viruelas, y por otros a la prohibición de la poligamia y mudanzas de costumbres, tengo fundamentos más sólidos en la historia para persuadirme que, aunque concurrieron las referidas causas, ninguna contribuyó tanto a su aniquilación como su misma rabiosa saña.

Así se infiere claramente de lo que por autoridad del Inca dejo apuntado en el capítulo segundo, y lo que también se deduce de la Historia de Herrera, que afirma que los indios, por no conocer nuevos encomenderos, se alzaban y huían a las montañas, donde es constante se quitaban la vida por no experimentar el castigo o volver a la sujeción que, aunque fuese muy moderada y suave, la estimaría su preocupación o libertinaje como penosa y tiránica. A más que siendo en los hombres tan diversos los genios como los rostros, no dudo tuviesen muchas razones para temer la severidad y rigor de algunos encomenderos, y que eligieran ciegamente la muerte, aun más bien que la servidumbre a que se veían reducidos, ahorcándose de los árboles, como expresa el citado Inca. Exceso que solicitó atajar la piedad de nuestro Soberano entonces reinante, tomando entre otros expedientes favorables, propios de su real y cristiano corazón, el de mandar los pusiesen en perfecta libertad, y los dejasen cultivar por sí mismos la tierra; pero ni aun este remedio tuvo el efecto de mejorarlos, porque debía de ser ya incurable la enfermedad, o porque no se aplicó como debía el medicamento.

Ello es cierto que mucho tiempo después de expedida la real orden que cita Herrera continuaban con horrible demasía el desafuero de los isleños, pues habiendo sido despachado aquel año de 1531, todavía se experimentaba la desgracia después del de 1538, en que arribó a Cuba Hernando de Soto, Adelantado de la Florida, como testifica Garci Laso, cuyas palabras, aunque parecen enunciar que entonces tuvo principio aquel desorden, lo que debe entenderse de ellas es que por aquel tiempo tomó más fuerza el mal, y se dieron en ahorcar, como él dice, todos. De suerte que a la sazón que él escribía apenas se encontraban algunos.
De la aserción de un autor tan verídico como el citado se convence bien que la principal causa que influyó para la aniquilación de estos naturales fué, como dejo asentado arriba, su mismo desatinado furor, el cual despobló la Isla de innumerables vivientes, y llenó el abismo de casi infinitos habitantes... ${ }^{51}$.

No estará solo Arrate en su consideración de la autoinmolación de los indígenas, lo que lo diferencia de otros autores dieciochescos radica en la valoración de la amplitud del fenómeno. Robertson lo tendrá en cuenta y lo aceptará en el recuento de las causas de la depresión demográfica en las islas del Caribe. Lo mismo hará el padre Nuix en Reflexiones imparciales sobre la bumanidad de los españoles en las Indias (1782), considerándolo un factor más, particular este de la blanda condición de los amerindios, junto con los generales atribuibles a cualquier proceso de conquista sean la violencia, la enfermedad, el trabajo forzado, la desaparición de los medios tradicionales de subsistencia, etc. Mayor variación representa el juicio de Alexander Von Humbolt ${ }^{52}$ al interesarse más que en el dato en la interpretación del fenómeno:

La manía de ahorcarse familias enteras en las cabañas y en las cavernas, de que habla Garcilaso, era sin duda por efecto de la desesperación; sin embargo, en lugar de contristarse al contemplar la barbarie del siglo $\mathrm{XVI}$, se ha querido disculpar a los conquistadores, atribuyendo la desaparición de los indígenas á su gusto por el suicidi ${ }^{53}$.

Por su parte, Viscardo cita por extenso al Inca Garcilaso para demostrar la ingratitud de España hacia los conquistadores y la obsesiva persecución de la Corona hacia los españoles americanos basándose, paradógicamente, en el ajusticiamiento de Tupac Amaru en 1572 y el destino deparado a indígenas y mestizos. El patricio cubano y el jesuita expulso se unirían en su defensa del conquistador y en la autoridad que le conceden al cronista:

Consultemos nuestros anales de tres siglos y allí veremos la ingratitud y la injusticia de la corte de España, su infidelidad en cumplir sus contratos, primero con el gran Colombo y después con los otros conquistadores que le dieron el imperio del nuevomundo, bajo condiciones solemnemente estipuladas. Veremos la posteridad de aquellos hombres generosos abatida con el desprecio, y manchada con el odio que les ha calumniado, perseguido y arruinado. Con 
algunas simples particularidades podrían hacer dudar de este espíritu persecutor, que en todo tiempo se ha señalado contra los Españoles Americanos, leed solamente lo que el verídico Inca Garcilaso de la Vega escribe en el segundo tomo de sus Comentarios, Libro VIII, cap. 17...54.

Si centramos la atención en la recepción que la obra del Inca tuvo en algunos autores extranjeros observaremos que tampoco en ellos está resuelta la fiabilidad que le otorgan al cronista y siguen dándose drásticas oscilaciones, las mismas que se extienden en esencia hasta nuestros días, en lo que respecta a la valoración de su obra. Un viajero ilustrado como Charles-Marie de La Condamine tratará de referir los asuntos americanos ateniéndose «siempre a las pruebas evidentes ${ }^{55}$, aquellas que fue acumulando desde que en 1736 iniciara el viaje patrocinado por la Academia de Ciencias de París para medir en Ecuador los grados terrestres y averiguar cabalmente la forma y tamaño de la Tierra, de la que parte la relación leída el 28 de abril de 1745 . Frente a la historia filosófica del setecientos, La Condamine buscó la veracidad del dato en el que apoyar sus conclusiones, irritándole sobremanera la tendencia a la especulación crítica, la profusión de opiniones personales, ya común en la época, y el desprecio sorprendentemente generalizado hacia el hecho positivo ${ }^{56}$. Por eso sus autoridades preferidas serán los testigos fidedignos, es decir, los que han experimentado las cosas que refieren junto a aquellos a los que el autor les concede un mayor grado de veracidad por saber de lo que hablan. Entre esas autoridades estará el Inca, mas que nada para asuntos geográficos, por ejemplo para probar que el Marañón y el Amazonas son un mismo río; no así para cuestiones antropológicas o lingüísticas porque si bien no encuentra inferior la naturaleza americana a ninguna otra, diferente es su consideración de la condición humana y bien distinta de la que el Inca expresó en su momento -«Bien sé que todos o la mayor parte de los indios de la América Meridional son embusteros, crédulos, encaprichados con lo maravilloso...» ${ }^{57}$-. La Condamine traza una semblanza general y negativa del carácter de los indios que observa, apoyada fundamentalmente en lo visto en Perú. Pero la caracterización no se ciñe a la situación del siglo XVIII sino que se convierte en una valoración de la idiosincrasia indígena al advertir que en el mismo estado están los indios explotados, los libres o los amparados en las Misiones. No sería entonces una forma de ser marcada por la historia sino por el temperamento. La insensibilidad que les achaca «nace, sin duda, del corto número de sus ideas que no se extienden más allá de sus deseos ${ }^{58}$, por tanto, si su capacidad intelectual está mermada las diversas lenguas con las que se expresan, adolecerán de esta misma carencia. Al analizar el caso peruano citará a Garcilaso sin saber si juzgarlo por mendaz o lamentarse de la degeneración sufrida por la antigua lengua del Perú:

Todas las lenguas de la América Meridional de las que tengo alguna noción son muy pobres; muchas son enérgicas y susceptibles de elegancia, singularmente la antigua lengua del Perú; pero a todas les faltan vocablos para expresar las ideas abstractas y universales, prueba evidente del poco progreso realizado por el espíritu de estos pueblos. Tiempo, duración, espacio, ser, substancia, materia, cuerpo, todas estas palabras y muchas más no tienen equivalentes en sus lenguas; no solamente los nombres de los seres metafísicos, sino los de los seres morales, no pueden expresarse entre ellos más que imperfectamente y por largas perífrasis. No tienen palabras propias que respondan exactamente a las de virtud, justicia, libertad, agradecimiento, ingratitud. Todo esto parece muy difícil de compaginar con lo que Garcilaso cuenta de la educación, de la industria, de las artes, del gobierno y del ingenio de los antiguos peruanos. Si el amor a la patria no le hizo imaginarlo, preciso es convenir que estos pueblos han degenerado mucho de sus antepasados. En cuanto a las otras naciones de la América Austral, no se sabe que hayan salido nunca de la barbarie ${ }^{59}$.

La perplejidad en la que se sitúa el naturalista francés pasa a ser un juicio poco favorable en la Historia de América (1777) de William Robertson. El inglés tiene en alta estima las obras de Pedro Cieza, Agustín de Zárate y Diego Fernández, mientras al Inca le opondrá contradictorios reparos. Si bien comienza considerando que «su autoridad es de mucho peso» ${ }^{60}$, al valorar positivamente la inmediatez de su testimonio con la conquista, su ascendencia indígena y su competencia lingüística - «hablaba muy bien la lengua de los Incas» ${ }^{61-}$; pasará, sin solución de continuidad, a infravalorar los Comentarios reales por no ir más allá de lo aportado por los historiadores españoles, haciendo una lectura literal del propósito expuesto por el propio Inca que, de

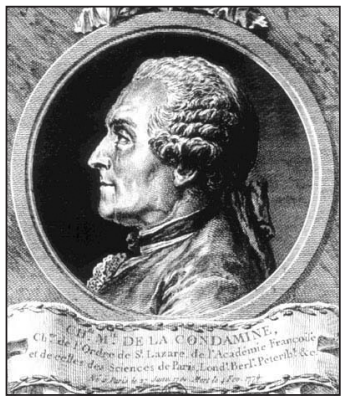

La Condamine.

54

Juan Pablo Viscardo, Carta a los españoles americanos, en Miquel Batllorir (estudio y ed.), El abate Viscardo. Historia y mito de la intervención de los jesuitas en la independencia de Hispanoamérica, Madrid, MAPFRE, 1995, pp. 335-336.

55

Charles-Marie de La Condamine, Viaje a la América meridional, Federico Ruiz Morcuende (trad.), Madrid, Espasa Calpe, 1999 , p. 83

56

«La comunicación del Orinoco y del Amazonas, recientemente averiguada, puede pasar, por tanto, por un descubrimiento en Geografía, porque aunque la unión de estos dos ríos esté marcada exactamente en los mapas antiguos, todos los geógrafos modernos la suprimieron en los nuevos, como si se hubiesen puesto de acuerdo y se tratara de una cosa quimérica para los que parece ser que debían ser los mejor informados de su realidad. Probablemente no es la primera vez que apariencias y conjeturas plausibles, apoyadas en hechos atestiguados por las relaciones de viaje, el espíritu de crítica, llevado demasiado lejos, las ha negado decisivamente, cuando, si acaso, lo más que podía hacerse era dudar de ellas", ibid., pp. 78-79.

57

lbid., p. 73.

58

lbid., pp. 39-40.

59

Ibid., pp. 40-41

60

William Robertson, Historia de América, Burdeos, Pedro Beaume, 1827, vol. III, «Notas y esplicaciones», nota 29 , p. 348.

61

ld.

Recepciones de la obra del Inca Garcilaso en el siglo XVIII VIRGINIA GIL AMATE 


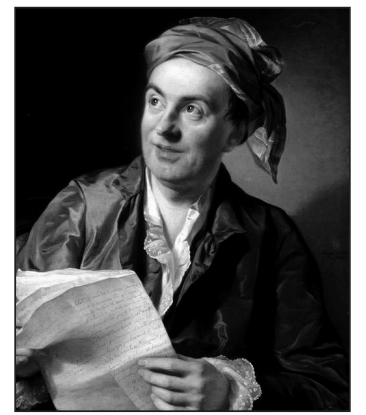

Jean François Marmontell.

62

ld.

63

lbid., pp. 348-349.

64

Ibid., nota 35, p. 354.

65

Robertson se refiere a la entrevista en Cajamarca entre Francisco Pizarro y Atahualpa, ibid., p. 352.

66

Ibid., nota 29, p. 349.

67

Ibid., nota 35, p. 352.

68

ld.

69

Ibid., nota 29, p. 346.

70

Garcilaso de la Vega, Inca, Historia General del Perú. Segunda parte de los Comentarios Reales de los Incas, ed. Ánge Rosenblat, pról. José de la Riva Agüero, Buenos Aries, Emecé, 1944, Libro III, cp. IX, p. 267 Sobre el dominio de la preceptiva histórica del Renacimiento en el Inca Garcilaso pueden consultarse los estudios clásicos de Aurelio Miró Quesada, El Inca Garcilaso y otros estudios garcilasistas, Madrid, Ediciones de Cultura Hispánica, 1971 y José Durand, El Inca Garcilaso de América, Lima, Biblioteca Nacional del Perú, 1988

71

William Robertson, op. cit., nota 35, p. 354 .

Recepciones de la obra del Inca Garcilaso en el siglo XVIII VIRGINIA GIL AMATE sobra es conocido, no es más que una forma de presentación acorde al tópico de la falsa modestia burlada en cada página por el cronista. Robertson juzgará los Comentarios reales precisamente como meros "comentarios", lastrados por el apocamiento de su autor, por la velada sospecha sobre su apropiación de la obra de Blas Valera y, lo que es peor, por sus escasas luces en asuntos indígenas:

....su obra puede ser estimada como un comentario de los escritores españoles que han tratado de la historia del Perú, compuesto de citas tomadas de los autores de que he hablado; y esta es la idea que él mismo da de sus escritos, en el lib. I, cap. 10. No solamente les sigue de una manera servil en la relación de los hechos, sino que no manifiesta mayor instrucción que sus guias en la esplicación de las instituciones y ceremonias de sus antepasados, como se vé cuando habla de los quipos, que lo hace poco mas ó menos como Acosta, y cuando cita un ejemplo de la poesía de los peruanos, que es un mal retazo que copió de Blas Varela, uno de los primeros misioneros cuyas memorias nunca han sido publicadas... ${ }^{62}$.

A eso suma ser uno de los pocos autores dieciochescos que encuentra defectos en el arte retórica del Inca-«Por lo demas, es inútil buscar en los comentarios del Inca el menor orden ${ }^{63}-$. Lo considera, además, un cronista poco escrupuloso en la confrontación de los hechos narrados - «su falta de atención y su inexactitud ordinarias» ${ }^{64}-$ y confirma los temores del Inca al juzgarlo apasionado de su mitad indígena - «Garcilaso de la Vega, muy solícito de justificar a los Peruanos sus compatriotas del crimen de haber querido acabar con Pizarro y sus compañeros, no teme menos acusar á los Españoles de haber tenido mala conducta con el Inca» ${ }^{65}$-. Si bien el grado de veracidad de las dos partes de los Comentarios reales fue una cuestión polémica a lo largo del siglo, el debate no recaía en la capacidad de juicio achacada al cronista. La lucidez del Inca, ya fuera tendenciosa para algunos, estaba a salvo de dudas, no así para Robertson, claro antecedente de los que, con posterioridad, lo consideraron un autor en exceso imaginativo, proclive a las ficciones y negado para el discurso histórico, que lo encontrará carente del «discernimiento necesario para distinguir lo fabuloso de lo verosímil ó verdadero» ${ }^{66}$. Puede ser que este juicio negativo emane del disímil planteamiento que ambos historiadores tienen sobre los hechos y sus protagonistas. De los habitantes del Tahuantinsuyo, pueblo civilizado por los Incas en los Comentarios reales, habituados a las conquistas y dotados de un áurea moral que no los separa de los cristianos, reducidos, en la Historia de la América, a "pueblos salvajes» y por ello «falsos y artificiosos» ${ }^{67}$; a la misma representación narrativa de Francisco Pizarro, héroe principal de la hazaña para Garcilaso, que por pura preceptiva histórica no puede ver mermada su talla humana en las plumas de los historiadores y un «aventurero tan osado y tan poco escrupuloso» ${ }^{68}$ para Robertson, carente de la mínima formación, «el vencedor ignorante del Perú» ${ }^{69}$, lo llama, siendo esta una de las particularidades sobre Pizarro, exhibida sin ambages por distintos autores, que más soliviantaban a Garcilaso, al mostrar de manera descarnada los bajos orígenes de los Pizarro, produciendo una anomalía narrativa entre el carácter edificante del discurso histórico y la realidad de los hechos, por lo que Garcilaso optaba por sacrificar estos detalles porque «de un príncipe tal, que puede igualarse con todos los de la fama, no se permite dezir cosas semejantes, aunque fueran verdades» ${ }^{70}$.

Finalmente, la dificultosa, cuando no imposible, comunicación entre españoles e indígenas, punto fundamental tanto para la explicación de los hechos históricos como para sopesar la misma valía de su obra en el Inca Garcilaso, no es achacada por Robertson a lo que el Inca apuntó, esto es, al desconocimiento de la lengua peruana por parte de los españoles, sino atribuida a la natural falta de comprensión entre dos pueblos situados en fases diferentes de desarrollo intelectual y social, donde los indígenas tendrían el signo menos:

Si se da crédito á los historiadores españoles, sus compatriotas eran tenidos en muchas partes de la América por seres bajados del cielo; pero en este caso, asi como en otros muchos á que puede dar lugar un comercio entre dos naciones cuyos progresos en la civilización son muy desiguales, las ideas de los que hablan son muy distintas de las de los que escuchan; porque el idioma de las lenguas americanas es tal, ó tal más bien la simpleza de los que las hablan, que cuando veian una cosa que no habian conocido hasta entonces, y cuyo orígen ignoraban, decian que era bajada del cielo ${ }^{71}$. (v. III, p. 354)

El planteamiento de Robertson será contrario al Inca pero está dotado de coheren- 
cia interna. No sucederá lo mismo con la utilización de la autoridad de Garcilaso por parte de Jean François Marmontel cuando en absoluto comparte el sentido histórico de los Comentarios reales en el delirio narrativo que preside Los incas o la destrucción del imperio del Perú (1777). La diferencia esencial radica en que mientras Robertson trazaba una historia de América desde presupuestos ideológicos y bases historiográficas antitéticas a las que en su día utilizó el Inca, la novela de Marmontel maneja el marco histórico como un mero escenario en el que dar rienda suelta a algunas inquietudes del Siglo de las Luces. Lo de menos es la fidelidad histórica, lo de más las ideas, siendo estas la representación de un gobierno que aspira a la felicidad del pueblo, de los gobernantes como gestores del bien común, la promoción del conocimiento y de las artes útiles, la defensa de la agricultura como base del desarrollo económico, la condena del lujo, el contrato social que exige ser útiles a los ciudadanos, etc. envuelto en la vía hiperestésica ilustrada y endosado al incario. Lo curioso es que Marmontel, en el prólogo, considera que ha elaborado una ficción ajustada a la verdad esencial, la marcada por los hechos efectivamente acaecidos:

En cuanto a la forma de esta obra considerada como una produccion literaria, no se como definirla. Hay muchas verdades para que sea una novela, y no hay las necesarias para formar una historia. Seguramente no he tenido la pretencion de hacer un poema. En mi plan, la accion principal no ocupa mas que un pequeño espacio; todo es análogo, aunque á una cierta distancia; es menos el tegido de la fábula que el hilo de un simple discurso, cuyo fondo es histórico, al que mezclo algunas ficciones compatibles con lo verdadero de los hechos ${ }^{72}$.

Y apuntalará esa ilusión histórica salpicando la novela de notas en las que remite a sus pretendidas fuentes y autoridades, citando con mediana profusión al Inca. Sin embargo, apenas comparte con Garcilaso la caracterización de los reyes naturales del Tahuantinsuyo como los civilizadores de la barbarie preincaica, la negación de los ritos cruentos y el retrato laudatorio de Pizarro. Ni siquiera hay coincidencias en la representación del esplendor del incario porque Marmontel utiliza como punto de vista el paternalismo bondadoso y así el señorío de los Incas le parecerá positivo en su simpleza hasta el punto de que uno de los personajes, el indígena Pilpatoé, pueda considerar a los pueblos vernáculos de América menos «ilustrados e industriosos», frente a los europeos dotados de «luces» y «conocimientos útiles» ${ }^{73}$ inexistentes entre los pueblos amerindios. De ahí que en el texto no se escatime el apelativo «salvajes» para referirse a los indígenas, sean Incas, caciques, vasallos de alguno de los imperios prehispánicos o miembros de cualquier tribu.

De todo ello resulta una reconstrucción de la conquista bien diferente a la que en su día hizo Garcilaso, no ya por las desaforadas licencias que se permite Marmontel, sino porque el novelista, en términos ideológicos, sigue la orientación marcada por Bartolomé de las Casas, siendo ésta absolutamente contraria al sentido histórico de las obras de Garcilaso. Desde el prólogo, y a lo largo de toda la novela, Marmontel exculpa a España, a los monarcas hispánicos y a las leyes españolas de los desmanes producidos en Indias. En línea lascasiana, los responsables de la crueldad colonizadora son, salvo poéticas excepciones, la población española destacada en Indias. Si Garcilaso se esmeró desde La Florida en no denigrar globalmente a ninguno de los bandos enfrentados en el decurso histórico, Marmontel no dudará a la hora de trazar su hostil semblanza de los autores de la conquista:

Es preciso no olvidar, tampoco, que los españoles que acompañaron á Cristobal Colon en la espedición eran de la hez del pueblo, la canalla. La miseria, la avaricia, la disolucion, el desórden, un valor tan desesperado, y sin brida como sin pudor, mezclado de orgullo y de bajeza, formaban el carácter de esta soldadesca, indigna de servir ni enarbolar las banderas de una nacion noble y generosa. A la cabeza de esta turba iban voluntarios sin disciplina y sin costumbres, que no conocian otro honor que el valor, otro derecho que la espada, ni otro objeto digno de sus servicios que el pillaje... ${ }^{74}$.

El punto de vista de Garcilaso al reconstruir el pasado inmediato, el que coincide con la fundación del Perú virreinal y el cronista identifica con su propia biografía en la demarcación temporal «mis tiempos», tan repetida en los Comentarios reales, no traza un cuadro infamatorio de los conquistadores, luego
72

Jean François Marmontel, Los incas o la destrucción del imperio del Perú, Francisco Antonio de Cabello y Mesa (trad.), Barcelona, Imprenta de Juan Oliveres, 1937, vol. I, pp. XXXII-XXXIII.

73 Ibid., p. 44.

74 Ibid., p. XVII
Recepciones de la obra del Inca Garcilaso en el siglo XVIII VIRGINIA GIL AMATE 
Gian Rinaldo Carli, Cartas americanas dirigidas por el conde Gian Rinaldo Carli a su sobrino el Marqués de Piedra-Losa, desde el año 1777 al de 1779 México, Imprenta de Mariano de Zúñiga y Ontiveros, 1821, Carta XIV, p. 9. La traducción, la Advertencia preliminar y las notas de esta edición se atribuyen a Fernando Pimentel Ixtliulxuchilt, pseudónimo de Agustín Pomposo Fernández.

77 Ibid., Carta XIV, p. 8.

Recepciones de la obra del Inca Garcilaso en el siglo XVIII VIRGINIA GIL AMATE transformados en «vezinos», es decir, la parte de la protosociedad virreinal ocupada por el colectivo de españoles principales, porque es precisamente ese tiempo histórico el que el Inca rememora con la amargura de lo que pudo haber sido el nuevo orden político. Más allá de los cruentos enfrentamientos entre los españoles, Garcilaso acepta el cambio como connatural al devenir histórico, por eso la recuperación idealizada del incario no tiene carga política sino que funciona como sueño de perfección. Lo que sí tiene carga política porque entraña, en el nuevo orden hispánico, una fuerte denuncia de cariz americanista es el lamento por la oportunidad perdida en la construcción de un Perú distintivo, mestizo en la esfera cultural y heterogéneo en la poblacional. Su propia vida, hasta el matrimonio de su padre con Luisa Martel de los Ríos en 1549 y, en el plano institucional, el lapso temporal que media desde la conquista hasta el ajusticiamiento de Tupac Amaru en 1572 prueban, en la segunda parte de los Comentarios reales, que ese Perú existió y su desarrollo fue truncado por las autoridades estatales y virreinales y por una legislación, paradójicamente las Leyes Nuevas, contraria a los intereses y las características virreinales. Nada de eso percibe Marmontel, enfrascado en representar el bien y el mal alrededor de los amoríos de Don Alonso y la vestal Cora, mientras apuntala los tópicos más usados sobre la conquista. Y menos puede entender que Garcilaso apostara por una entidad nueva que, bajo la aceptación del vasallaje a la corona, aspirara a su propia autonomía en la que las medidas dictadas en la península no interfirieran el desarrollo de las relaciones entre los distintos grupos humanos, ya fuera para protegerlos (en este caso a los indígenas), ya fuera para cortar sus aspiraciones (en este caso a los criollos y mestizos), o ya fuera para anatematizar su comportamiento (en este caso el del colectivo de españoles).

La carga ideológica que va del marco referencial del Renacimiento, en el que está el Inca, al de la Ilustracción, en el que está Marmontel, hace que el francés escriba contra el fanatismo encarnado en la facción triunfante española y trace una igualdad, que habría sobresaltado a Garcilaso, entre las creencias y los dioses indígenas y la fe de los católicos. Y permita, en este caso en la esfera política, que la perfecta organización del Tahunatinsuyo fijada por Garcilaso, se vea felizmente revolu- cionada con la entrada de las leyes de la razón. Sirva como ejemplo el lance del capítulo XL dedicado al juicio a Cora por haber violado sus votos, en el que la ardorosa defensa de la libertad y el orden basado en la ley natural, producen una convulsión en la multitud y cambio radical en Atahualpa:

Durante este discurso de Alonso, un murmullo confuso anunciaba entre la multitud la revolución que se operaba en los ánimos, y el monarca aprovechó del instante de decidir para siempre. Tiene razón, grita, y la razón comanda á la ley misma. No, pueblo, yo debo confesarlo; esa ley cruel no viene del sabio Manco: no fueron sino sus sucesores los que la hicieron; ellos creyeron agradar á su dios; pero se engañaron. El error cesa, y la verdad recobra sus derechos. Demos gracias al estrangero que nos desengaña, nos ilustra y nos hace revocar una ley inhumana... ${ }^{75}$.

No menos imaginativo se mostró Gian Rinaldo Carli al servirse del incario para desgranar su fiera utopía dieciochesca. En ella un orden tan perfecto como inhumano preside una sociedad satisfecha de sí misma e inmutable por voluntad de un Estado vigilante y benefactor. Una comunidad donde no existe el lujo, ni la codicia, ni la vagancia, ni el libertinaje, ni se admiten extranjeros que vengan a alterar con sus novedades la invariable armonía grupal. Sin embargo, en la descripción de este panorama, Carli incurre en sustanciales contradicciones, porque se afanará en defender la base igualitaria que preside el Tahuantinsuyo mientras describe un sistema monárquico fuertemente jerarquizado; asimismo, celebra que en el incario fuera «como imposible que se cometiera» ${ }^{76}$ delito alguno por ser las leyes, en la Carta XIII, respetadas, asumidas y por lo tanto obedecidas, para cambiar el argumento en la Carta XIV en la que lo que funciona es más bien un sistema parapolicial en el que la punición severa actúa como aviso represivo que no sobresalta a Carli, puesto que en ello ve la voluntad de los Incas de "prevenir o evitar los delitos, lo cual hace todo el objeto de la paternidad ${ }^{77}$. Ahí radica la base ideológica sobre la que sustenta Carli sus paradójicos planteamientos: la quietud social no es otra cosa que el sometimiento a unos gobernantes que han sabido sacarle el máximo partido a la alienación colectiva. Ese parece ser el arte de gobernar. Por supuesto, a esas alturas del siglo XVIII el autor no puede obviar que el origen divino del poder de los Incas, de donde deriva 
«el fuerte amor y la adoración ácia el propio soberano ${ }^{78}$, es una colosal manipulación pero le parece benéfica para el orden social. ¿Qué hay, entonces, de Garcilaso en esta libérrima exposición comentada del incario? Apenas nada, aunque el cronista sea la autoridad más citada en lo referente al orden social, a las creencias, la arquitectura, la ingeniería, los usos sociales, la riqueza natural, la poesía o la benignidad del clima. Y así, considerando en todo momento el testimonio del Inca como verdadero, adulterará a su antojo tal legado. Por ejemplo, siguiendo a Garcilaso relatará, en estilo divulgativo, la cosmogonía del origen de los Incas. Al igual que el cronista destacará la condición fabulosa de esa genealogía, pero mientras el interés de Garcilaso residía en mostrar la propia construcción histórica de los indígenas y comprender la visión del mundo que tales leyendas de origen contenían; Carli la detalla con el fin de resaltar, en un siglo que iba liberándose del peso de la fe, las bondades de la unión entre el poder terrenal y las creencias religiosas, la utilidad de la cohesión entre la ley civil y la esfera espiritual y la conveniencia de la teoría del origen divino del poder real para la perfecta quietud de un grupo humano.

Por su parte, en lo que toca al sistema educativo, que le parece en esencia viable, descoyunta el sistema igualitario que antes había celebrado para señalar una doble vía formativa, una instrucción básica para el pueblo centrada en la enseñanza de la religión y la humilde sumisión; y una educación para los nobles, con un amplio catálogo de disciplinas. En una vulgarización completa del legado de Garcilaso los «Amautis» transmitían a estos jóvenes «lo poco que sabían de astronomía, de música y de poesía» ${ }^{79}$. No estaba en esto Carli demasiado alejado de Pauw aunque se presentara como su detractor; sólo suavizó, beatíficamente, la expresión descarnada del naturalista, para compartir básicamente su opinión.

En ninguno de estos famosos textos europeos, ni en los críticos más recalcitrantes ni en los aparentemente bien intencionados de- fensores, halló calado alguno el propósito de Garcilaso al describir el incario, la conquista y el proceso de pérdida de una realidad mestiza en el Perú. Marmontel creía, o quería hacer creer, que su novela no desdibujaba la historia pero lo que hizo fue contribuir a fijar, debido al gran éxito de Los incas.., una imagen de la conquista y del Tahuantinsuyo en un público en el que ya no pesaba el interés por la verdad histórica. Espectadores y lectores de Europa y América ${ }^{80}$, ilustrados españoles, como Meléndez Valdés ${ }^{81}$, o patriotas americanos, como Miranda ${ }^{82}$, participaban, con mayor o menor conciencia, de la moda incásica que se iría extendiendo en el último cuarto del siglo XVIII.

Pero quizá lo más curioso del proceso no sea sólo que algunos autores extranjeros quisieran creerse sus propias ficciones o deslumbrarse con un incario despojado de su condición histórica, convertido en una pantomima tan feliz y bondadosa, tan diferente a la movilidad política -esta, por lo visto, sólo europea-, hasta el punto de desear, tal cual hace Carli, con mucho voluntarismo y ninguna práctica, «peruanizarse»:

...estoy tan empapado de la idea del antiguo gobierno del Perú, que me parece que soy un peruviano: permitidme á lo menos desear que en cualquier otro lugar de nuestro globo se constituyera un sistema igual para poder yo marchar á gozar una completa felicidad en el resto de vida que me quedare, lejos de los tumultos populares, y á cubierto de aquellas tempestades que el proceloso mar de la política, lleno de escollos y de sirtes, son inevitables, tal ve aun á los mas diestros navegantes ${ }^{83}$.

Quizá, digo, no sea eso lo más sorprendente, sino la aceptación por parte de algunos americanos de semejantes adulteraciones. Fueran historiadores de peso, como Juan Ignacio Molina, que consideraba recopilado en las Cartas americanas «todo lo que conduce para dar una idea verdadera de ambas Américas» ${ }^{84}$, o personajes un tanto extravagantes como Agustín Pomposo, que al publicar, en 1821, ocho de las cartas (de la XIII a la XX,

de Telémaco, cosa como suya, de un estilo tan delicado como el de los cuentos y llena de máximas y sentimientos de humanidad, pero que exagera con exceso nuestras crueldades y apoya fuertemente la tolerancia. Yo esta clase de libros los leo con el mayor gusto, porque nada me embelesa tanto como las máximas de buena moral, y éstas, mejor esparcidas y como sembradas en una obra llena de imaginación y primores», apud, José F. Montesinos, Introducción a una historia de la novela en España en el siglo XIX. Seguida del esbozo de una bibliografía española de traducciones de novelas. 1800-1850, Madrid, Castalia, 1982, pp. 14-15. Para la recepción positiva que entre los ilustrados españoles tuvo la obra de Marmontel véase Elena de Lorenzo: Gaspar Melchor de Jovellanos, Obras Completas. XII. Escritos sobre Literatura, Oviedo, Ayuntamiento de Gijón / Instituto Feijoo de Estudios del Siglo XVIII / KRK Ediciones, 2006 , p. 39.

Postura bien contraria fue la de Cadalso, riéndose de la fama adquirida por Marmontel, en la Tercera Lección de Los eruditos a la violeta: "Aplaudid a Mr. Marmontel. Es el moralista de estado más digno de la cátedra de prima. No hay petimetre ni petimetra, abate distraído, soldado de paz, filósofo extravagante, heredero gastador, ni viuda de veinte años, que no tenga un curso completo de moral en los primorosos cuentos de este finísimo académico», op. cit., p. 82.

82

Véase Jesús Díaz-Caballero, «Nación y patria: las lecturas de los «Comentarios reales» y el patriotismo criollo emancipador», Revista de Crítica Literaria Latinoamericana, Año XXX 59 (ler. semestre 2004), pp. 81-107.

83

Gian Rinaldo Carli, op. cit., Carta XIX, p. 55

84

Juan Ignacio Molina, Prefacio a Compendio de la Historia geografica, natural y civil de Chile, t. 1, Domingo Joseph de Arguellada Mendoza (trad.) Madrid, Antonio de Sancha, 1788, p. XVIII.

tubre-diciembre 1984), pp. 54-66.

81

En carta a Jovellanos fechada el 27 de abril de 1779,
Meléndez Valdés apuntaba: "Después de Robertson acabo de leer una obra de Marmontel cuyo título es Los incas... especie de novela y poema épico como Las aventuras
Recepciones de la obra del Inca Garcilaso en el siglo XVIII 
Fernando Pimentel Ixtliulxuchilt [Agustín Pomposo], "Advertencias» a Gian Rinaldo Carli, op cit., p. [2]. junto con un fragmento de la XXI) consideraba no ya verosímil sino verdadero lo descrito por Carli y, entusiasmado, lo proponía como plan de gobierno para los indígenas, porque quizá «no se pueda hoy acomodar á todas las clases» ${ }^{85}$, una vez consolidado el «Renaciente Imperio Mexicano». Este era también el curioso viaje de regreso de Garcilaso a América, volando, sin respeto alguno hacia el texto fijado por el cronista, en los sueños de los hastiados de tanta civilización, para llegar a manos de los que con facilidad inaudita podían abstraerse de la realidad más inmediata. 